\title{
Application of Numerical Algorithm Procedure to Classification of Expansive Soil
}

\author{
Xiao-Min $\mathrm{HE}^{\mathrm{a}}$, Zhan-Bin WANG ${ }^{\mathrm{b},{ }^{,}, \mathrm{Na} Z \mathrm{ZHAO}^{\mathrm{c}} \text {, Ju LUO }}$ \\ ${ }^{1}$ Yangtze River Scientific Research Institute, Key Laboratory of Geotechnical Mechanics and \\ Engineering of The Ministry of Water Resources, Wuhan 430010, China \\ ${ }^{2}$ Postgraduate in Geoengineering Department of Soil Engineering, Yangtze River Scientific Research \\ Institute, Wuhan, China \\ ahxm04280428@163.com, b532153689@qq.com, ${ }^{c_{3}} 346881786 @ q q . c o m,{ }^{d}$ luoju317@126.com \\ ${ }^{*}$ Corresponding author
}

Keywords: Expansive soil, Free swelling Ratio, Clustering, Fuzzy C Means Algorithm, Membership.

\begin{abstract}
Due to the complexity of geological conditions and human factors of indoor physical and mechanical tests, evaluation of swelling potential of expansive soil shows significant characteristics of uncertainty, noise and multi-modal, Therefore its identification and classification is still a complex problem unsolved. This paper chooses liquid limit, plasticity index, clay content Less than $0.005 \mathrm{~mm}$ and free expansion rate as the evaluation indicators of expansive soil, after the determination of the value of each indicator, fuzzy $\mathrm{C}$ means algorithm model for level evaluation of expansive soil is established, then the author writes the evaluation process and uses this program on the cluster analysis of expansive soil. After compared with the indoor tests of expansive sample, the results indicate that fuzzy C means algorithm could achieve clustering of Nanyang expansive soil accurately and efficiently.
\end{abstract}

\section{Introduction}

Expansive soil is a kind of high-plasticity clay with multi-fracture and significant swell-shrink characteristics in the natural geological formation process. The clay composition, being mainly comprised of strong hydrophilic minerals, has the property of water-swelling, water loss shrinking, repeated deformation, and strength degradation [1]. The strong expansive soil, taken as weak expansive soil or non-expansive soil, leaves behind the hidden danger for the engineering construction. On the other hand, the weak expansive soil or non-expansive soil, taken as strong expansive soil, increases the number of engineering measures and leads to huge engineering waste. Therefore people attention to the problem of the identification and classification of expansive soil for its important practical significance [2, 3].

Fuzzy clustering has become the mainstream of cluster analysis and an important branch of unsupervised pattern recognition due to its objective reflection of the real world by means of intermediary description of sample class.

All manuscripts must be in English, also the table and figure texts; otherwise we cannot publish your paper. Compared with the Hard C Means algorithm (HCM), the Fuzzy C Means algorithm could obtain more abundant clustering information and reflect the actual distribution of samples more precisely. And so far, FCM algorithm is one of the most widely used Fuzzy Clustering methods. FCM has been applied to many fields $[4,5,6]$, such as large-scale scientific data analysis, data mining, vector quantization, image segmentation and pattern identification, since Bezdek [7] put forward the algorithm. This paper chooses 4 physical-mechanical indices and determined their boundary values. An expand-shrink class evaluation model of expansive soil and an evaluation program are built in this paper. The program could complete cluster analysis to Nanyang expansive soil, and the analysis results has been given to the test of validation. 


\section{The Basic Physical Characteristic of Nanyang Expansive Soil}

According to the core samples, cubic block samples and disturbed expansive soil samples from the Nanyang test section of the Central Project of Water Adjustment from South to North, the basic physical-mechanical property of them and its swelling-shrinkage behavior are performed on the Table 1 . The record format in the table: maximum-minimum

Tab. 1 Basic Physical-mechanical Property of the Nanyang Expansive Soil

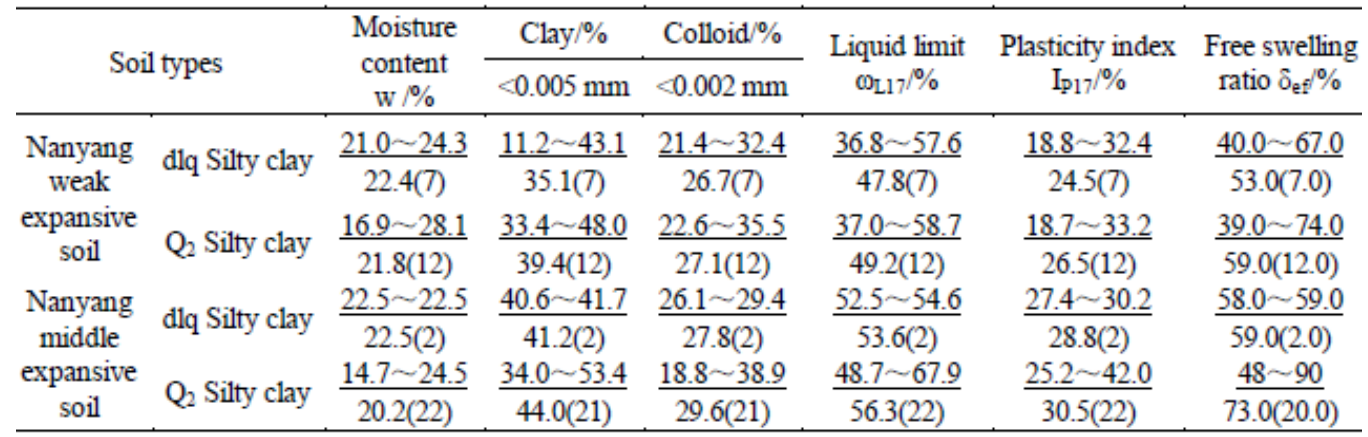

The Nanyang $\mathrm{Q}_{2}$ silty clay and Nanyang dlq silty clay is middle expansive soil and weak expansive soil based on the assessing criterion of free swelling ratio in technical code for buildings in swelling soil zone (GBJ112-87) [8].

The liquid limit, plasticity index, clay content, colloid content, and free swelling ratio of Nanyang middle expansive soil are significant figure than weak expansive soil. The liquid limit and plasticity index increase with the growing free swelling ratio. The $\mathrm{Q}_{2}$ silty clay of both Nanyang middle expansive soil and Nanyang weak expansive soil, and the dlq silty clay of Nanyang middle expansive soil belong to high liquid limit clay, and the dlq silty clay of Nanyang weak expansive soil belongs to low liquid limit clay.

\section{The Swelling-shrinkage Mechanism Indexes Analysis}

Some of the single classification indexes, such as natural moisture content, free swelling ratio, vary in the background of different objective environment and human factors, and maybe the same expansive soil samples are identified as the different swelling-shrinkage grade. To have a reasonable discretion and classification, the detailed studies to related indexes must be needed. And multiindex conjoint analysis is an ideal way to reflect the behavior of expansive soil. This paper choose the physical indexes of liquid limit, plasticity index, clay and colloid content, free swelling ratio as assessing criteria. Tests and analysis testify that the 4 indexes could reflect the swelling-shrinkage behavior in the mass.

\section{Free Swelling Ratio}

Free swelling ratio is one of the most direct measuring indexes that reflect the swelling-shrinkage behavior of soil. The free swelling ratio increases with the growing montmorillonite content and diminishes with the decreasing kaolinite content. In the meantime, the free swelling ratio have the advantages of shorter period and being more simple in test operation, so that the discretion and classification would be quick and easy. Thus, better experimental results are obtained commonly as the free swelling ratio being criteria index.

\section{Critical Moisture Content}

Including the indexes of liquid limit and plasticity limit, the crucial water content coefficient reflects the sensitivity of soil-water interaction and the hydrophilic property of soil to a certain degree. Normally, expansive soil is a kind of clay with high plasticity and high contractility. The swelling potential increases with the growing liquid limit and the decreasing shrinking limit. Therefore, taken as the assessing criteria of expansive soil, the water ratio limit eigenvalue is adoptable. On the other hand, the plasticity index could reveal the gradation composition, dispersion characteristics, and interaction between cation and clay mineral. Its grading standards have been proven completely according to the massive previous tests and its stability is good as the assessing criteria index. 


\section{Gradation Composition}

Gradation composition is the basic behavior index that reflects material composition of expansive soil. Generally, the higher clay and colloid content would lead to higher montmorillonite content, stronger hydrophilicity, larger specific surface area, better dispersity, larger dispensability. As a consequence, the clay and colloid content could also be taken as the assessing criteria to identify the expansive soil and non-expansive soil.

\section{The Fuzzy C-Means Clustering Algorithm with Two Stages}

\section{The Judging Achievement of Swelling Potential}

The liquid limit, plasticity index, clay content, colloid content, and free swelling ratio are chosen as the judging indexes of expansive soil. According to the laboratory tests of the expansive soils of the Central Project of Water Adjustment from South to North, the standard values are given in Table 2 taking references from the discrimination and classification method of plasticity graph [9], specifications for design of highway subgrades [10], technical code for buildings in expansive soil regions [8]. The judging indexes of the 29 Nanyang expansive soil samples are listed in Table 3.

Tab. 2 Standard Values of Evaluation Indexes of Expansive Soil

\begin{tabular}{ccccc}
\hline Judging indexes & $\begin{array}{c}\text { Clay content } \\
\%\end{array}$ & Liquid limit $\omega_{L} / \%$ & Plasticity index $I_{P} / \%$ & $\begin{array}{c}\text { Free swelling } \\
\text { ratio } \delta_{e f} / \%\end{array}$ \\
\hline $\begin{array}{c}\text { Weak } \\
\text { expansive } \\
\text { soil }\end{array}$ & 35 & 45 & 25 & 53 \\
$\begin{array}{c}\text { Middle } \\
\text { potential gring }\end{array}$ & 45 & 55 & 30 & 75 \\
$\begin{array}{c}\text { expansive } \\
\text { soil } \\
\begin{array}{c}\text { Strong } \\
\text { expansive } \\
\text { soil }\end{array}\end{array}$ & 50 & 70 & 40 & 95 \\
\hline
\end{tabular}

Tab. 3 The Judging Indexes and Swelling Potential of Nanyang Expansive Soil

\begin{tabular}{|c|c|c|c|c|c|c|c|}
\hline Soil types & $\begin{array}{c}\text { Sample } \\
\text { numeber }\end{array}$ & $\begin{array}{l}\text { Sample depth } \\
/ \mathrm{m}\end{array}$ & $\begin{array}{c}\text { Clay } \\
\text { content } \\
/ \%\end{array}$ & $\begin{array}{l}\text { Liqiud limit } \\
\qquad \omega_{I} \%\end{array}$ & $\begin{array}{l}\text { Plasticity } \\
\text { index } I_{P} / \%\end{array}$ & $\begin{array}{l}\text { Free swelling ratio } \\
\qquad \delta_{\phi f} \%\end{array}$ & $\begin{array}{l}\text { Swelling } \\
\text { potential }\end{array}$ \\
\hline \multirow{20}{*}{$\mathrm{Q}_{2}$ Silty Clay } & $\mathrm{SS} 03-\mathrm{Y} 1$ & $5.65 \sim 5.85$ & 33.4 & 37.0 & 18.7 & 39 & weak \\
\hline & $\mathrm{SS} 03-\mathrm{Y} 2$ & $9.85 \sim 10.05$ & 40.8 & 40.2 & 21.2 & 56 & weak \\
\hline & $\mathrm{SS} 12-\mathrm{Y} 1$ & $6.05 \sim 6.25$ & 41.1 & 46.5 & 26.2 & 59 & weak \\
\hline & $\mathrm{SS} 12-\mathrm{Y} 2$ & $9.05 \sim 9.25$ & 37.4 & 45.4 & 25.6 & 46 & weak \\
\hline & $\mathrm{SS} 12-\mathrm{Y} 3$ & $12.15 \sim 12.35$ & 35.8 & 40.8 & 20.2 & 58 & weak \\
\hline & $\mathrm{SS} 16-\mathrm{Y} 1$ & $4.75 \sim 4.95$ & 38.8 & 50.2 & 25.7 & 60 & middle \\
\hline & SS16-Y2 & $6.55 \sim 6.75$ & 42.9 & 55.4 & 30.3 & 60 & middle \\
\hline & SS16-Y3 & $14.45 \sim 14.65$ & 39.0 & 52.1 & 26.7 & 50 & weak \\
\hline & SS19-Y1 & $10.55 \sim 10.75$ & 42.4 & 53.6 & 25.2 & 73 & middle \\
\hline & SS23-Y1 & $1.15 \sim 1.35$ & 42.8 & 53.9 & 28.2 & 78 & middle \\
\hline & $\mathrm{SS} 23-\mathrm{Y} 2$ & $2.75 \sim 2.95$ & 43.1 & 53.1 & 28.1 & 73 & middle \\
\hline & SS23-Y3 & $7.65 \sim 7.85$ & 51.0 & 65.3 & 37.1 & 74 & strong \\
\hline & SS23-Y4 & $16.45 \sim 16.65$ & 38.2 & 52.7 & 27.5 & 68 & middle \\
\hline & $\mathrm{SS} 26-\mathrm{Y} 1$ & $4.35 \sim 4.55$ & 38.6 & 53.8 & 28.3 & 72 & middle \\
\hline & SS26-Y2 & $11.55 \sim 11.75$ & 45.8 & 67.9 & 42.0 & 86 & strong \\
\hline & $\mathrm{SS} 26-\mathrm{Y} 3$ & $15.85 \sim 16.05$ & 46.4 & 62.4 & 33.7 & 80 & strong \\
\hline & SS26-Y4 & $17.95 \sim 18.15$ & 39.1 & 53.4 & 28.1 & 70 & middle \\
\hline & SS29-Y2 & $6.95 \sim 7.15$ & 44.1 & 60.1 & 31.8 & 66 & middle \\
\hline & SS31-Y1 & $3.25 \sim 3.45$ & 46.4 & 54.2 & 30.1 & 67 & middle \\
\hline & SS31-Y2 & $5.15 \sim 5.35$ & 34.0 & 50.3 & 26.1 & 68 & middle \\
\hline \multirow{9}{*}{ dlq Silty Clay } & $\mathrm{SS} 03-\mathrm{Y} 3$ & $1.45 \sim 1.75$ & 35.5 & 36.8 & 18.8 & 49 & weak \\
\hline & $\mathrm{SS} 03-\mathrm{Y} 4$ & $2.25 \sim 2.45$ & 43.1 & 41.3 & 21.8 & 40 & weak \\
\hline & SS03-Y5 & $3.35 \sim 3.55$ & 39.8 & 38.0 & 19.1 & 49 & weak \\
\hline & SS08-Y1 & $1.75 \sim 1.95$ & 11.2 & 55.2 & 22.7 & 58 & weak \\
\hline & SSOS-Y2 & $3.75 \sim 3.95$ & 33.9 & 54.6 & 30.4 & 49 & weak \\
\hline & $\mathrm{SS} 12-\mathrm{Y} 4$ & $2.05 \sim 2.25$ & 41.9 & 57.6 & 32.4 & 67 & middle \\
\hline & $\mathrm{SS} 16-\mathrm{Y} 4$ & $1.75 \sim 1.95$ & 40.6 & 51.4 & 26.4 & 48 & weak \\
\hline & $\mathrm{SS} 28-\mathrm{Y} 1$ & $1.75 \sim 1.95$ & 41.7 & 54.6 & 30.2 & 59 & middle \\
\hline & $\mathrm{SS} 32-\mathrm{Y} 1$ & $0.95 \sim 1.15$ & 40.6 & 52.5 & 27.4 & 58 & middle \\
\hline
\end{tabular}


Tab. 4 Membership Matrix in Different Iterations

\begin{tabular}{|c|c|c|c|c|c|c|c|c|c|}
\hline $\begin{array}{l}\text { Sample } \\
\text { number }\end{array}$ & & No. 5 & & & No.10 & & & No. 20 & \\
\hline $\begin{array}{l}\text { Standard } \\
\text { Sample } 1\end{array}$ & 0.0003 & 0.9997 & 0.0000 & 0.0000 & 1.0000 & 0.0000 & 0.0000 & 1.0000 & 0.0000 \\
\hline $\begin{array}{l}\text { Standard } \\
\text { Sample } 2\end{array}$ & 0.0038 & 0.0000 & 0.9962 & 0.9630 & 0.0001 & 0.0369 & 0.9917 & 0.0000 & 0.0082 \\
\hline $\begin{array}{l}\text { Standard } \\
\text { Sample } 3\end{array}$ & 0.0078 & 0.0004 & 0.9918 & 0.0006 & 0.0000 & 0.9994 & 0.0004 & 0.0000 & 0.9996 \\
\hline SS03-Y1 & 0.0011 & 0.9989 & 0.0000 & 0.0006 & 0.9994 & 0.0000 & 0.0006 & 0.9994 & 0.0000 \\
\hline $\mathrm{SS} 03-\mathrm{Y} 2$ & 0.0057 & 0.9942 & 0.0000 & 0.0028 & 0.9972 & 0.0000 & 0.0020 & 0.9980 & 0.0000 \\
\hline $\mathrm{SS} 03-\mathrm{Y} 3$ & 0.0002 & 0.9998 & 0.0000 & 0.0001 & 0.9999 & 0.0000 & 0.0001 & 0.9999 & 0.0000 \\
\hline $\mathrm{SS} 03-\mathrm{Y} 4$ & 0.0008 & 0.9992 & 0.0000 & 0.0006 & 0.9994 & 0.0000 & 0.0006 & 0.9994 & 0.0000 \\
\hline SSO3-Y5 & 0.0001 & 0.9999 & 0.0000 & 0.0001 & 0.9999 & 0.0000 & 0.0001 & 0.9999 & 0.0000 \\
\hline SS08-Y1 & 0.5226 & 0.4491 & 0.0283 & 0.3241 & 0.6634 & 0.0125 & 0.2869 & 0.7022 & 0.0109 \\
\hline SSO8-Y2 & 0.1933 & 0.8060 & 0.0007 & 0.0361 & 0.9638 & 0.0001 & 0.0235 & 0.9764 & 0.0001 \\
\hline SS12-Y1 & 0.8901 & 0.1097 & 0.0002 & 0.5385 & 0.4613 & 0.0001 & 0.3644 & 0.6355 & 0.0001 \\
\hline $\mathrm{SS} 12-\mathrm{Y} 2$ & 0.0000 & 1.0000 & 0.0000 & 0.0000 & 1.0000 & 0.0000 & 0.0000 & 1.0000 & 0.0000 \\
\hline SS12-Y3 & 0.0187 & 0.9812 & 0.0001 & 0.0058 & 0.9942 & 0.0000 & 0.0039 & 0.9961 & 0.0000 \\
\hline SS12-Y4 & 0.9834 & 0.0001 & 0.0165 & 0.9999 & 0.0000 & 0.0001 & 1.0000 & 0.0000 & 0.0000 \\
\hline SS16-Y1 & 0.9989 & 0.0011 & 0.0000 & 0.9551 & 0.0448 & 0.0000 & 0.8922 & 0.1078 & 0.0001 \\
\hline SS16-Y2 & 0.9997 & 0.0002 & 0.0001 & 0.9989 & 0.0010 & 0.0001 & 0.9978 & 0.0022 & 0.0001 \\
\hline SS16-Y3 & 0.0334 & 0.9666 & 0.0001 & 0.0051 & 0.9949 & 0.0000 & 0.0029 & 0.9971 & 0.0000 \\
\hline SS16-Y4 & 0.0091 & 0.9908 & 0.0000 & 0.0021 & 0.9979 & 0.0000 & 0.0014 & 0.9986 & 0.0000 \\
\hline SS19-Y1 & 0.7409 & 0.0004 & 0.2587 & 0.9996 & 0.0000 & 0.0004 & 0.9999 & 0.0000 & 0.0001 \\
\hline SS23-Y1 & 0.0067 & 0.0000 & 0.9933 & 0.9010 & 0.0002 & 0.0987 & 0.9724 & 0.0002 & 0.0274 \\
\hline SS23-Y2 & 0.5152 & 0.0002 & 0.4846 & 0.9996 & 0.0000 & 0.0003 & 0.9999 & 0.0000 & 0.0001 \\
\hline SS23-Y3 & 0.0021 & 0.0000 & 0.9979 & 0.0048 & 0.0000 & 0.9952 & 0.0069 & 0.0000 & 0.9930 \\
\hline SS23-Y4 & 1.0000 & 0.0000 & 0.0000 & 1.0000 & 0.0000 & 0.0000 & 1.0000 & 0.0000 & 0.0000 \\
\hline SS26-Y1 & 0.9622 & 0.0001 & 0.0377 & 1.0000 & 0.0000 & 0.0000 & 1.0000 & 0.0000 & 0.0000 \\
\hline SS26-Y2 & 0.0026 & 0.0001 & 0.9974 & 0.0000 & 0.0000 & 1.0000 & 0.0000 & 0.0000 & 1.0000 \\
\hline SS26-Y3 & 0.0000 & 0.0000 & 1.0000 & 0.0000 & 0.0000 & 1.0000 & 0.0002 & 0.0000 & 0.9998 \\
\hline SS26-Y4 & 0.9981 & 0.0000 & 0.0019 & 1.0000 & 0.0000 & 0.0000 & 1.0000 & 0.0000 & 0.0000 \\
\hline SS28-Y1 & 0.9996 & 0.0003 & 0.0001 & 0.9962 & 0.0038 & 0.0001 & 0.9916 & 0.0083 & 0.0001 \\
\hline SS29-Y2 & 0.9092 & 0.0003 & 0.0905 & 0.9988 & 0.0001 & 0.0011 & 0.9993 & 0.0001 & 0.0006 \\
\hline SS31-Y1 & 0.9728 & 0.0002 & 0.0270 & 0.9999 & 0.0000 & 0.0001 & 1.0000 & 0.0000 & 0.0000 \\
\hline SS31-Y2 & 0.9993 & 0.0003 & 0.0004 & 0.9992 & 0.0008 & 0.0001 & 0.9988 & 0.0012 & 0.0001 \\
\hline $\mathrm{SS} 32-\mathrm{Y} 1$ & 0.9980 & 0.0020 & 0.0000 & 0.9509 & 0.0491 & 0.0001 & 0.8898 & $0.11 p 1$ & 0.0001 \\
\hline
\end{tabular}

The standard values of 3 judging grades are regarded as 3 expansive soil samples in table 2 , and the samples from 1 to 29 could be recorded as from 4 to 32 if the swelling-shrinkage behavior from weak to strong are treated as $1,2,3$. The data points set is $\mathrm{X}=\{\mathrm{x} 1, \mathrm{x} 2, \cdots, \mathrm{xn}\} \subset \mathrm{RS}$, and $\mathrm{m}=1.5, \mathrm{c}=3, \varepsilon=$ 0.0001 . The clustering analysis of soil samples is a process programmed by FCM algorithm. The iteration terminates when the number $1=7$. The membership matrix in different iterations sees Table 4 .

From the figure 1, it can be seen that the iteration process of FCM algorithm has a faster convergent speed, especially when the iteration numbers are 20, and the bound norm of the difference of adjacent membership matrixes fall to near 0 when the matrixes maintain a constant value approximately. The classification is already evident in samples. The element uij in the membership matrix $U$ indicates the membership degree of the ith $(i=1,2, \cdots, n)$ data point corresponding to the $j$ th $(j=1,2, \cdots, c)$ category, and it is easy to determine the category ownership by following the maximum membership principle of fuzzy set. From table 5, it can be concluded that the samples SS03-Y1, SS03-Y2, SS03-Y3, SS03-Y4, SS03-Y5, SS08-Y2, SS12-Y2, SS12-Y3, SS16-Y3, SS16-Y4 are classified as the weak expansive soil 
for its being same category with the standard sample 1, and the other samples' classifications are given in Table 3.

There are 3 samples, classified as strong expansive soil in Table 3, is different with the result of free expansive ratio classification standard. This is because the liquid limit, plasticity index and the clay and colloid content of samples SS26-Y3, SS23-Y2, and SS23-Y3, are close to characteristic values of expansive soil, and the strength characteristics of expansive soil has a strong link with the above-mentioned indexes. The multiindex identification method in this paper has the higher credibility because of the strong influence of objective environment, human factors, noise and randomness of single index (free expansive ratio).

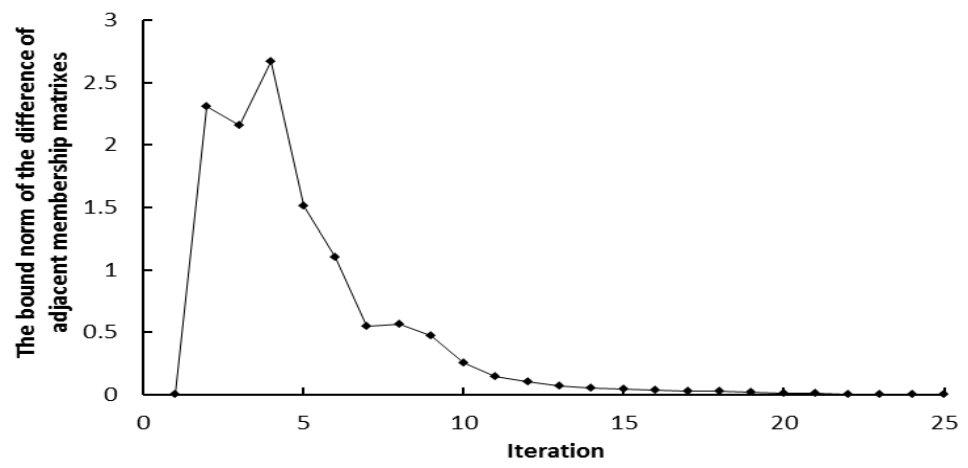

Fig. 1 Membership Matrix Convergence

\section{Test Evaluation}

The middle and weak expansive soil are mainly distributed throughout Nanyang, and some typical samples are chosen to test by drained shear triaxial test. Calibration graphs are prepared by plotting moisture against intensity parameters in Fig. 2.

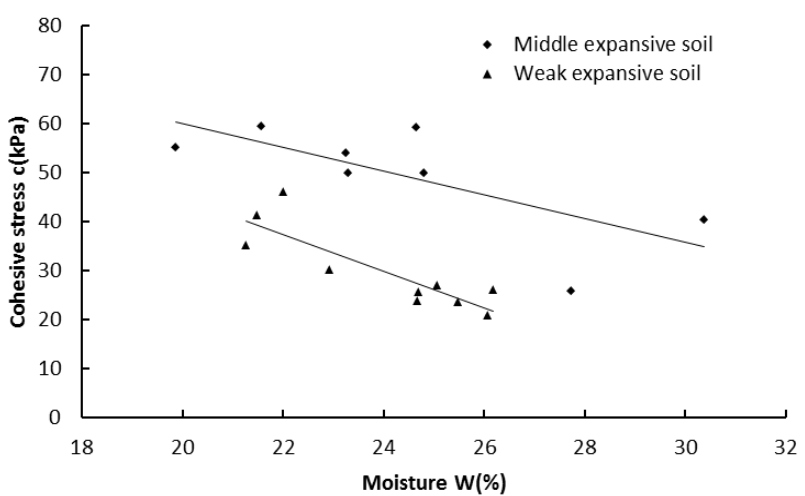

(a) The cohesive stress - moisture curves

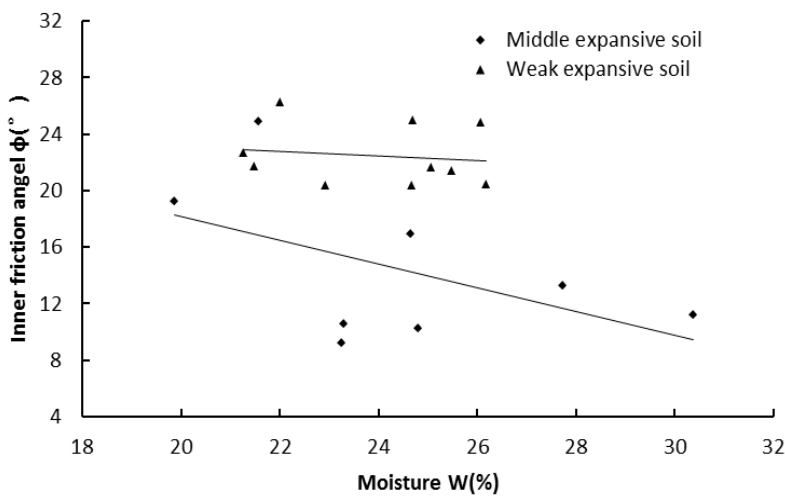

(b) The inner friction angel - moisture curves

Fig. 2 Relationship Curves of Strength Parameters and Moisture

From Fig.2, it can be concluded that the cohesion strength of middle expansive soil is higher than weak expansive soil, and the coefficient of internal friction is the other way around. Both of them have a very clear line drawn, which distinguish the middle and weak expansive soil precisely. The classification has good feasibility and provides reference for future expansive soil project.

\section{Conclusion}

The swelling potential classification has the characteristics of uncertainty, noise and multiplex mode because of its complexity of the geological conditions and human factors of physical and mechanical tests. The classification and discrimination of expansive soil is a complex question unsolved perfectly. Based on the experimental results, the in-depth exploration of physical and mechanical indexes reflecting the swelling and shrinking mechanism and characteristics promotes swelling potential classification of 
Nanyang expansive soil. And the testification of the classification is conducted by laboratories. The followings are the main conclusions.

(1) The basic physical and mechanical characteristics, swelling-shrinkage properties libarotary are conducted according to core samples, cubic block samples and disturbed expansive soil samples from Nanyang. The Nanyang Q2 silty clay and Nanyang dlq silty clay is middle expansive soil and weak expansive soil by free expansive ratio classification standard.

(2) According to the properties of uncertainty, noisy and multimode of the expansive soil in the routine test, to get a kind of flexible partition method- the fuzzy C-Means clustering algorithm, the fuzzy set is introduced in cluster analysis, and the ordinary hard and fast clustering target function is expanded into fuzzy clustering criterion function.

(3) The liquid limit, plasticity index, clay content, colloid content, and free swelling ratio are chosen as the judging indexes of expansive soil. And an expanded and shrink class evaluation model of expansive soil and an evaluation program are built in this paper. The program could complete cluster analysis to Nanyang expansive soil, and the analysis results has been given to the test of validation.

\section{References}

[1]Yong-fu XU, Song-yu LIU, Strength of unsaturated soils and its application, Southeast University Press, Nanjing, 1999.

[2]Shi-wen LIAO, Expansive soil and railway engineering, China Railway Publishing House, Beijing, 1984.

[3]Shan-xiong CHEN, Song YU, Ling-wei KONG, et al., Study on approach to identification and classification of expansive soils, Rock and Soil Mechanics. 26(2005)1895-1900.

[4]Bezdek J. C., Pattern Recognition with Fuzzy Objective Function Algorithms, Plenum Press, New York, 1981.

[5]Pal N. R., Bezdek J. C., On clusters validity for the fuzzy C means mode, IEEE Trans. on Fuzzy Systems, 28(1995)370-379.

[6]Li-xin WANG, A Course in Fuzzy System and Control, Tsinghua University Press, Beijing, 2003.

[7]Bezdek J. C., Pattern Recognition with Fuzzy Objective Function Algorithms, Plenum Press, New York, 1981.

[8]Ministry of Housing and Urban-Rural Development of the People's Republic of China, Technical code for buildings in expansive soil regions(GBJ112-87), China Planning Press, Beijing, 2003.

[9]Gui-zhi MA, The application of plasticity chart to Shanxi special soils distribution, Journal of Xi'an College of Geology. 17(1995)87-89.

[10]Institute of Ministry of Communication of China second Highway Consultant, Specifications for Design of Highway Subgrades, China Communications Press, Beijing, 2004. 